\title{
Skin-Disease Specific and Generic Psychometric Measures in Patients with Psoriasis
}

\author{
Beata Kowalewska (D) - Barbara Jankowiak • Elżbieta Krajewska-Kułak • \\ Rafał Milewski · Marek Sobolewski
}

Received: July 13, 2021 / Accepted: September 8, 2021 / Published online: September 28, 2021

(C) The Author(s) 2021

\begin{abstract}
Introduction: Psychosocial problems of patients with chronic dermatoses, such as psoriasis, add to their somatic ailments, which results in the lack of illness acceptance, lowered self-esteem, deteriorated quality of life, and an array of somatic comorbidities. The aim of this study was to analyze the effect of psoriasis on the quality of life, sense of stigmatization, selfesteem, and satisfaction with life in patients with psoriasis.
\end{abstract}

Methods: The study was based on a short survey prepared by the authors and five validated scales: Dermatology Life Quality Index (DLQI), 6-Item Stigmatization Scale, 33-Item Feelings of Stigmatization Questionnaire, Rosenberg SelfEsteem Scale (SES), and Satisfaction With Life Scale (SWLS). The study included 111 patients

B. Kowalewska $(\bowtie) \cdot$ B. Jankowiak ·

E. Krajewska-Kułak

The Department of Integrated Medical Care,

Medical University in Białystok, 7A MC

Skłodowskiej Str., 15-096 Białystok, Poland

e-mail: beata.kowalewska@umb.edu.pl

R. Milewski

Doctoral Studies at Faculty of Health Sciences, Department of Primary Healthcare, Medical

University of Bialystok, Białystok, Poland

M. Sobolewski

Faculty of Management, Rzeszow University of

Technology, Rzeszów Poland with psoriasis (46.8\% women and 53.2\% men). The inclusion criteria of the study were the diagnosis of plaque psoriasis and written informed consent to participate.

Results: DLQI scores ranged between 0 and 28 points (pts) (mean 10.8 pts). Mean stigmatization scores determined with the 33- and 6-Item Stigmatization Scale were 81.6 pts and 7.5 pts, respectively. The mean SWLS score for the study group (18.5 pts) was slightly below the average. The mean score SES of 27 pts implies that the study respondents' self-esteem level was slightly above the average.

Conclusions: Satisfaction with life turned out to be significantly modulated by overall stigmatization level on the 33-Item Stigmatization Scale (the stronger the sense of stigmatization, the lower the satisfaction with life) and education (respondents with higher education presented with higher satisfaction with life than those with non-higher education).

Keywords: Psoriasis; Quality of life; Satisfaction with life; Self-esteem stigmatization 


\section{Key Summary Points}

\section{Why carry out this study?}

Skin lesions cause stigmatization of patients with psoriasis, contribute to the deterioration of their life quality and psychosocial problems.

Psoriasis may be also associated with a plethora of somatic complications and increased socioeconomic burden.

We assumed that the levels of self-esteem and satisfaction with life determine the quality of life and sense of stigmatization of an individual. We hypothesized that patients with psoriasis present with high stigmatization levels, which translates into poor quality of life. These two problems are aggravated by lower satisfaction with life and lower self-esteem and can be modulated by sociodemographic variables.

\section{What was learned from the study?}

Psoriatics presented with lowered quality of life measured with the DLQI, and their self-esteem and satisfaction with life were significantly modulated by the stigmatization level.

Localization of psoriatic lesions exerted a significant effect on only two components of the 33-Item Stigmatization Scale, Guilt and Shame and Positive Attitudes, and was not associated with the overall quality of life (DLQI) and other psychometric variables, SWLS and SES.

While the relationships mentioned above are relatively well understood, future research should verify whether and how they evolve in response to social changes, and if this evolution warrants the adjustment of psychotherapeutic approaches and/or modification of the forms and objectives of social campaigns supporting patients with psoriasis.

\section{INTRODUCTION}

Skin is the largest organ of the human body. It has many roles, among others being involved in thermoregulation, perception of external stimuli, and playing protective and esthetic roles. Appearance and condition of the skin are a "trademark" of each human being, given that they are visible to others; likewise, most dermatological diseases and skin lesions are easily noticeable, which has a profound effect not only on the psychological condition of patients but also on their social relations. Psoriasis is an example of a burdensome, incurable dermatosis. This is an inflammatory disease with a strong tendency to recur, which manifests primarily with skin lesions but may also involve nails and joints [1]. It is estimated that psoriasis affects $2-3 \%$ of the Polish population and approximately $2 \%$ of persons worldwide [2-7]. Psoriasis can be triggered by an array of extrinsic and intrinsic factors, including genetic and immunological predispositions, diet, some medications, infections, mechanical injuries, psychological stress, and traumatic experiences [8-13].

Contemporary humans are exposed to a mass media-promoted cult of striving for perfection in each aspect of life and socially desired young and pure body image. Any deviation from such a media-enforced concept is disapproved by the general public. As a result, persons who do not follow the promoted canon of beauty are not infrequently socially marginalized. Therefore, the presence of skin lesions being visible to others often leads to social rejection of the patients [14-19].

The visibility of skin lesions and frequent flares of psoriasis may provoke disgust and hostility towards the patients, as many laypersons are concerned that the condition may be contagious. As a result, the patients may be socially rejected, and some of them can even feel worthless or considered a threat by others. This mechanism contributes to emotional problems, distortion of body image and body self, depression, and fear of being stigmatized [20-23]. The sense of being worse, unattractive, and useless translates into a belief that life has 
no sense, whereas the inability to cope with everyday problems, stress, and negative emotions associated with the disease exacerbate psoriatic lesions [20-24]. Psychosocial problems of patients with chronic dermatoses, such as psoriasis, add to their somatic ailments, leading to the lack of illness acceptance, lowered selfesteem, deteriorated quality of life, and an array of somatic comorbidities (e.g., obesity, substance abuse, depression, cardiovascular diseases) [24-33] and sexual disorders (loss of libido, erectile problems, reluctance to undertake sexual activities) [22, 34, 35].

The aim of the study was to determine:

- Effect of psoriasis on the quality of life, sense of stigmatization, and self-esteem

- Satisfaction with life and self-esteem in patients with psoriasis

- Effect of sociodemographic variables and location of psoriatic lesions on skin diseasespecific and generic psychometric measures

We assumed that self-esteem and satisfaction with life determine the quality of life and stigmatization level in psoriasis. We hypothesized that patients with psoriasis present with a strong sense of stigmatization which contributes to a decrease in their quality of life. This relationship is more evident whenever the satisfaction with life and self-esteem of the patients are lower and is additionally modulated by sociodemographic variables. These associations are clinically relevant given that psoriasis is known to co-exist not only with somatic comorbidities but also with problems in psychological and social spheres. Moreover, psoriasis is a markedly more stigmatizing condition than diseases that cannot be noticed by others and even evoke sympathy, such as cardiovascular disorders and diabetes mellitus. It needs to be also stressed that difficulty coping with stressful situations and excessive emotional response are factors exacerbating the course of psoriasis, which is likely to be reflected by both the disease-specific and generic psychometric measures.

\section{METHODS}

\section{Participants}

The study included patients recruited at two private clinics of dermatology and medical cosmetology in Bialystok (Poland), headed by Prof. Wiaczesław Niczyporuk and Dr. Piotr Aleksiejczuk, respectively. The study group consisted of 111 patients with plaque psoriasis, among them $46.8 \%$ women and $53.2 \%$ men.

The inclusion criteria of the study were the diagnosis of plaque psoriasis and written informed consent to participate. The authors initially planned to obtain at least 200 complete surveys. However, collection of the study material was hindered because of the COVID-19 pandemic. Given the epidemic risk and related restrictions, the target number had to be reduced to 100 complete surveys. A total of 200 surveys were distributed, but some were not returned, and others missed some data or were returned incomplete as the respondents decided to withdraw from the study at the last minute. As a result, final response and rejection rates were $55.5 \%(N=111)$ and $44.5 \%(N=89)$, respectively.

The study was conducted in January and February 2020. The respondents received printed questionnaires along with the instructions on how to complete them. Most patients completed the surveys onsite, alone or with the assistance of the investigator. However, some respondents preferred to complete the survey at home; such persons were provided with a preaddressed stamped return envelope.

The research conforms with the Good Clinical Practice guidelines, and the procedures followed were in accordance with the Helsinki Declaration of 1975, as revised in 2000 (concerning the ethical principles for the medical community and forbidding release of the patient's name and initials, or the hospital evidence number). The study was reviewed and approved by the Bioethics Committee of the Medical University in Białystok (statute no. R-I002/285/2018). 


\section{Measures}

The study was based on a short survey prepared by the authors and several validated scales, including three psychometric scales analyzing the effects of psoriasis: Dermatology Life Quality Index (DLQI) developed by Finlay and Khan [29] and adapted to Polish conditions by Szepietowski et al. [36], 6-Item Stigmatization Scale by $\mathrm{Lu}$ et al. [37] in Polish adaptation by Hrehorów et al. [38], and 33-Item Feelings of Stigmatization Questionnaire by Ginsburg and Link [39] in Polish version by Hrehorów et al. [38], as well as two generic psychometric scales: Satisfaction With Life Scale (SWLS) by Diener, Emmons, Larsen, and Griffin [40], adapted to Polish conditions by Juczyński [41], and Rosenberg Self-Esteem Scale (SES) in Polish adaptation by Dzwonkowska, LachowiczTabaczek, and Łaguna [42].

\section{Sociodemographic Survey}

The authors' survey contained questions about the respondents' sociodemographic characteristics (gender, age, marital status, education, place of residence) and location of psoriatic lesions.

\section{Dermatology Life Quality Index}

DLQI is a validated scale to measure the impact of skin disease on the quality of life within a week preceding the study. The scale centers primarily around disability and functional impairment caused by the disease and, to a lesser extent, around the emotional aspect of the condition (only 1 out of 10 items) $[29,36]$. DLQI measures the negative impact of skin disease on the quality of life; hence, the higher the score, the more deteriorated the quality of life in a given patient. The scale consists of ten questions with the answers scored on a 4-point Likert-type scale: "very much" (3 pts), "a lot" (2 pts), "a little" (1 pt), and "not at all" (0 pts). The overall score can range between 0 and 30 pts $[29,36]$.

\section{6-Item Stigmatization Scale}

The 6-Item Stigmatization Scale consists of six single-choice questions, each with four possible answers: "not at all" (0 pts), "sometimes" (1 pt), "very often" (2 pts), and "always" (3 pts). The overall score can range between 0 (lack of stigmatization) and 18 pts (maximum stigmatization level); the higher the score, the higher the level of stigmatization, rejection, and embarrassment associated with a dermatological disease [37, 38].

\section{Feelings of Stigmatization Questionnaire}

The 33-Item Feelings of Stigmatization Questionnaire consists of 33 single-choice questions with answers scored from 0 to 5 pts: "definitely yes"(5 pts), "yes" (4 pts), "rather yes" (3 pts), "rather no" (2 pts), "no" (1 pt), and "definitely no" (0 pts). The overall score can range from 0 (lack of stigmatization) to $165 \mathrm{pts}$ (maximum stigmatization level). The higher the score, the stronger the sense of stigmatization in the respondent in the following six domains: Anticipation of Rejection, Feeling of Being Flawed, Sensitivity to the Opinions of Others, Guilt and Shame, Positive Attitudes, and Secretiveness [38, 39].

\section{Satisfaction With Life Scale (SWLS)}

The level of satisfaction with life was determined with the SWLS. The scale consists of five statements referring to lifetime experiences of the respondent, each with answers scored from 1 ("strongly disagree") to 7 pts ("strongly agree"). The overall score can range between 5 and 35 pts, with higher scores corresponding to greater satisfaction with life. The raw results can also be converted into the sten scores with 1-4, 5-6, and 7-10 sten corresponding to a low, moderate, and high level of satisfaction with life, respectively. Sten scale (ten standard)-a scale of the psychological test normalized so that the population mean is 5.5 and the standard deviation is 2 . There are 10 units on the scale. The current Polish standards for SWLS are raw score: 5-9 (1 sten); 10-11 (2 sten); 12-14 (3 
Table 1 Distributions of skin disease-specific and generic psychometric measures in patients treated for psoriasis

\begin{tabular}{|c|c|c|c|c|c|}
\hline Questionnaire/measure & & Mean & Std. dev. & Min & $\operatorname{Max}$ \\
\hline \multicolumn{6}{|l|}{ Skin disease-specific measures } \\
\hline DLQI & A measure of skin ailment severity & $10.8(9.4 ; 12.2)$ & 7.3 & 0 & 28 \\
\hline \multirow[t]{7}{*}{ 33-Item Stigmatization Scale } & Overall score & $81.6(77.0 ; 86.2)$ & 24.3 & 33 & 132 \\
\hline & Anticipation of rejection & $22.9(21.4 ; 24.3)$ & 7.6 & 7 & 40 \\
\hline & Feeling of being flawed & $13.3(12.1 ; 14.5)$ & 6.5 & 2 & 26 \\
\hline & Sensitivity to the opinions of others & $12.1(11.1 ; 13.2)$ & 5.5 & 1 & 28 \\
\hline & Guilt and shame & $14.0(13.2 ; 14.8)$ & 4.1 & 6 & 23 \\
\hline & Positive attitudes & $8.8(8.1 ; 9.6)$ & 3.8 & 1 & 17 \\
\hline & Secretiveness & $10.5(9.7 ; 11.3)$ & 4.4 & 3 & 20 \\
\hline 6-Item Stigmatization Scale & A measure of stigmatization & $7.5(6.6 ; 8.3)$ & 4.7 & 0 & 18 \\
\hline \multicolumn{6}{|l|}{ Generic measures } \\
\hline SWLS & A measure of satisfaction with life & $18.5(17.3 ; 19.7)$ & 6.5 & 6 & 35 \\
\hline SES & Self-esteem measure & $26.8(26.1 ; 27.5)$ & 3.6 & 16 & 36 \\
\hline
\end{tabular}

Table 2 Effect of sex on generic psychometric measures (mean with 95\% CI)

\begin{tabular}{|c|c|c|c|}
\hline \multirow[t]{2}{*}{ Psychometric measure } & \multicolumn{2}{|l|}{ Sex } & \multirow[t]{2}{*}{$p$} \\
\hline & Women $(N=52)$ & $\operatorname{Men}(N=59)$ & \\
\hline SWLS & $18.3(16.6 ; 20.0)$ & $18.7(16.9 ; 20.5)$ & 0.7410 \\
\hline SES & $26.0(24.9 ; 27.0)$ & $27.5(26.6 ; 28.4)$ & $0.0220^{*}$ \\
\hline
\end{tabular}

$p$ value was calculated using $t$ test; test probability: ${ }^{*} p<0.05$ - statistically significant relationship; ${ }^{* *} p<0.01-$ highly significant relationship; ${ }^{* * *} p<0.001$ - very highly statistically significant relationship

Table 3 Effect of education on generic psychometric measures (mean with 95\% CI)

\begin{tabular}{llll}
\hline Psychometric measure & Education & & $\boldsymbol{p}$ \\
\cline { 2 - 4 } & Non-higher $(\boldsymbol{N}=74)$ & Higher $(\boldsymbol{N}=\mathbf{3 7})$ & \\
\hline SWLS & $18.4(17.0 ; 19.8)$ & $18.7(16.2 ; 21.2)$ & 0.8284 \\
SES & $26.7(26.0 ; 27.4)$ & $26.9(25.5 ; 28.4)$ & 0.7534 \\
\hline
\end{tabular}

$p$ value was calculated using $t$ test 
Table 4 Relationships between the location of psoriatic lesions and skin disease-specific and generic psychometric measures

Psychometric measure

Location of psoriatic lesions

Absent $(N=34)$ Some body parts $(N=44)$ Entire body

$(N=33)$

Skin disease-specific measures (mean with 95\% CI)

DLQI

$10.7(8.4 ; 13.0)$

$10.7(8.3 ; 13.1)$

Overall score

$79.0(70.6 ; 87.5)$

$80.9(72.8 ; 88.9)$

Anticipation of rejection

$20.9(18.9 ; 22.9)$

$23.0(20.2 ; 25.7)$

Feeling of being flawed

$11.6(9.4 ; 13.7)$

$14.1(12.0 ; 16.2)$

$10.9(8.9 ; 12.8)$

$13.0(11.1 ; 14.8)$

$16.1(14.6 ; 17.6) \quad 12.8(11.7 ; 13.8)$

Guilt and shame

$9.8(8.3 ; 11.4)$

$7.7(6.6 ; 8.8)$

$9.8(8.4 ; 11.2)$

$10.4(9.1 ; 11.7)$

$6.6(4.9 ; 8.2)$

$8.1(6.6 ; 9.7)$

6-Item Stigmatization Scale

Generic measures (mean with 95\% CI)

SWLS

$17.8(15.4 ; 20.3) \quad 19.8(17.8 ; 21.8)$

$26.4(25.3 ; 27.4) \quad 27.5(26.3 ; 28.7)$

$11.1(8.5 ; 13.7)$

$85.2(77.7 ; 92.8)$

$24.7(22.2 ; 27.2)$

$14.0(11.9 ; 16.1)$

$12.3(10.7 ; 13.9)$

$13.5(12.1 ; 14.9)$

$9.3(8.2 ; 10.5)$

$11.3(9.6 ; 13.1)$

$7.5(6.1 ; 8.9)$

SES

0.9591

0.5630

0.1267

0.1756

0.2381

$0.0010^{* *}$

$0.0321^{*}$

0.3652

0.3558

$p$ value was calculated using ANOVA, test probability: ${ }^{*} p<0.05$ - statistically significant relationship; ${ }^{* *} p<0.01-$ highly significant relationship; ${ }^{* * *} p<0.001$ - very highly statistically significant relationship

Table 5 Correlations of skin-disease specific scales with SWLS and SES scores

Skin disease-specific measures

Generic psychometric measures

\begin{tabular}{lrr} 
& SWLS & SES \\
\hline DLQI & $-0.49\left(0.0000^{* * *}\right)$ & $-0.39\left(0.0000^{* * *}\right)$ \\
33-Item Stigmatization Scale (overall) & $-0.56\left(0.0000^{* * *}\right)$ & $-0.61\left(0.0000^{* * *}\right)$ \\
Anticipation of rejection & $-0.46\left(0.0000^{* * *}\right)$ & $-0.54\left(0.0000^{* * *}\right)$ \\
Feeling of being flawed & $-0.41\left(0.0000^{* * *}\right)$ & $-0.51\left(0.0000^{* * *}\right)$ \\
Sensitivity to the opinions of others & $-0.49\left(0.0000^{* * *}\right)$ & $-0.47\left(0.0000^{* * *}\right)$ \\
Guilt and shame & $-0.29\left(0.0021^{* *}\right)$ & $-0.28\left(0.0030^{* *}\right)$ \\
Positive attitudes & $-0.50\left(0.0000^{* * *}\right)$ & $-0.48\left(0.0000^{* * *}\right)$ \\
Secretiveness & $-0.36\left(0.0001^{* * *}\right)$ & $-0.44\left(0.0000^{* * *}\right)$ \\
6-Item Stigmatization Scale & $-0.44\left(0.0000^{* * *}\right)$ & $-0.45\left(0.0000^{* * *}\right)$ \\
\hline
\end{tabular}

(test probability: ${ }^{*} p<0.05$ - statistically significant relationship, ${ }^{* *} p<0.01$ - highly significant relationship, ${ }^{* * *} p<0.001$ - very highly statistically significant relationship) 
sten); 15-17 (4 sten); 18-20 (5 sten); $21-23$ (6 sten); 24-26 (7 sten); 27-28 (8 sten); 29-30 (9 sten); 31-35 (10 sten) [41].

\section{Rosenberg Self-Esteem Scale (SES)}

The SES measures the global level of self-esteem in the respondent. The scale consists of ten statements, each with answers scored from 1 ("strongly agree") to 4 pts ("strongly disagree"). The overall score can range between 10 and 40 pts. Reference tables can be used to convert the raw results into the sten scores, with 1-2, $3-4,5-6,7-8$, and 9-10 sten corresponding to a very low, low, moderate, high, and very high level of self-esteem, respectively [42].

\section{Statistical Analysis}

The results underwent statistical analysis with Statistica 13 software. The distributions of the psychometric measures were presented as descriptive statistics (arithmetic means with 95\% confidence intervals, standard deviations, minimum and maximum values). The significance of differences in the mean values of psychometric measures according to gender, education, and location of psoriatic lesions was verified with Student $t$ test (for two groups) or analysis of variance (ANOVA) (for three and more groups). Relationships between skin disease-specific and generic psychometric measures were analyzed on the basis of Pearson's coefficients of linear correlation. Total effects of skin disease-specific psychometric measures and demographic variables on SES and SWLS scores were verified on regression analysis.

The following explanatory variables were included in the two regression models with SWLS and SES as dependent variables:

- Skin disease-specific psychometric measures (33- and 6-Item Stigmatization Scales, DLQI)

- Demographic characteristics (age, gender, education)

- Location of psoriatic lesions

The two strongest predictors of the dependent variable in each model were identified using the stepwise regression method [43, 44].
The results of all analyses were considered significant at $p<0.05[43,44]$.

\section{RESULTS}

\section{Values of Psychometric Measures in the Entire Study Population}

DLQI scores ranged between 0 and 28 pts. The majority of the respondents presented with low DLQI scores, with a mean value of 10.8 pts. Mean stigmatization scores determined with the 33- and 6-Item Stigmatization Scale were 81.6 pts and 7.5 pts, respectively (Table 1 ).

The mean SWLS score for the study group (18.5 pts) was slightly below the average. The scores for the self-report SES instrument can range between 10 and 40 pts; hence, the mean score of 27 pts implies that the study respondents' self-esteem level was slightly above the average (Table 1).

\section{Relationships Between Generic Psychometric Measures and Clinicodemographic Characteristics}

We analyzed the effects of selected clinicodemographic factors on the values of generic psychometric measures, SWLS and SES. The list of explanatory variables included gender, age, education, duration of psoriasis, and location of psoriatic lesions. Male respondents presented with higher levels of satisfaction with life and higher self-esteem than women (Table 2).

Age did not correlate significantly with the satisfaction with life (SWLS) and self-esteem (SES) scores. A comparison of mean SWLS and SES scores for various age groups of patients did not show statistically significant differences.

Participants with higher education chose avoidance-focused style (SSU) and sought social contacts significantly more often than persons with non-higher education (Table 3 ).

Duration of psoriasis did not correlate significantly with the satisfaction with life (SWLS) and self-esteem (SES) scores, with the coefficients of linear correlation of -0.01 $(p=0.9546)$ and $0.05(p=0.5985)$, respectively. 

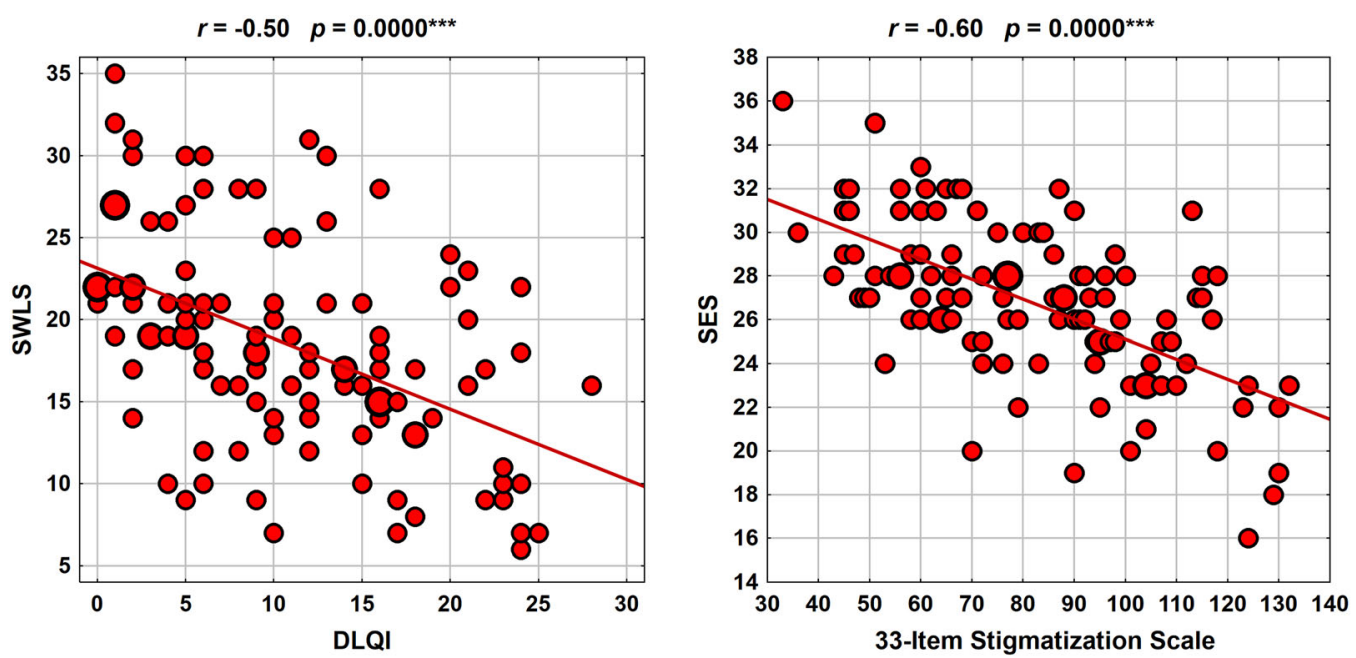

Fig. 1 Relationships between DLQI and SWLS scores and the overall score for the 33-Item Stigmatization Scale and SES score

We also analyzed the scores for psychometric measures according to the location of psoriatic lesions. The analysis included three groups of patients, without psoriatic lesions (30.63\%), with lesions covering only some body parts (39.64\%) and with lesions spread across the entire body (29.73\%). The significance of between-group differences was verified with ANOVA.

Among skin disease-specific psychometric measures, the location of psoriatic lesions exerted significant effects solely on two components of the 33-Item Stigmatization Scale, Guilt and Shame and Positive Attitudes. The location of psoriatic lesions was not associated with other skin disease-specific measures and did not significantly influence any generic psychometric measures (Table 4).

\section{Relationships Between Skin Disease- Specific and Generic Psychometric Measures}

We verified whether and how the values of the skin disease-specific scales (DLQI, both stigmatization scales) influenced the values of the generic psychometric measures, SWLS and SES. The results were presented as linear correlation coefficients.
The scores for skin disease-specific scales showed relatively strong correlations with the values of generic psychometric measures. The powers of DLQI and stigmatization scale correlations with SWLS and SES were similar. All correlations were inverse which implies that an increase in psoriasis-related discomfort had a detrimental effect on the overall well-being of the respondents measured with SWLS and SES (Table 5).

Relationships between DLQI and SWLS scores and the overall score for the 33-Item Stigmatization Scale and SES score are depicted in Fig. 1.

\section{Effect of Skin Disease-Specific Psychometric Measures and Clinicodemographic Characteristics on Generic Psychometric Measures}

None of the generic psychometric measures was significantly modulated by clinicodemographic characteristics of the patients, such as gender, age, education, location of psoriatic lesions, and duration of psoriasis.

SWLS scores turned out to be significantly modulated by the overall score for the 33-Item Stigmatization Scale (the stronger the sense of stigmatization, the lower the satisfaction with life, with a 1-pt increment in the stigmatization 
Table 6 Independent predictors of generic psychometric measures (SWLS, SES)

\begin{tabular}{llll}
\hline & $\boldsymbol{B}(\mathbf{9 5 \%} \mathbf{C I})$ & $\boldsymbol{p}$ & $\boldsymbol{\beta}$ \\
\hline SWLS & $R^{2}=34.8 \%, F=28.8, p=0.0000^{* * *}$ & & \\
33-Item Stigmatization Scale (overall) & $-0.158(-0.199 ;-0.116)$ & $0.0000^{* * *}$ & -0.59 \\
Education (higher vs. non-higher) & $1.253(0.215 ; 2.292)$ & $0.0185^{*}$ & 0.19 \\
SES & $R^{2}=40.5 \%, F=36.8, p=0.0000^{* * *}$ & & -0.93 \\
33-Item Stigmatization Scale (overall) & $-0.138(-0.185 ;-0.091)$ & $0.0000^{* * *}$ & 0.36 \\
Sensitivity to the opinions of others & $0.232(0.026 ; 0.438)$ & $0.0274^{*}$ & \\
\hline
\end{tabular}

Overall statistics: $R^{2}$, coefficient of determination (the percentage of the response variable variation that is explained by a model); Test statistic $F$ and $p$ value for assessment of significance of whole model

Results for each predictor variables: $B$, regression coefficient (with $95 \%$ confidence interval)

$p$, assessment of significance; $\beta$, standardize regression coefficient; test probability: ${ }^{*} p<0.05$ - statistically significant relationship, ${ }^{* *} p<0.01$ - highly significant relationship, ${ }^{* * *} p<0.001$ - very highly statistically significant relationship

score associated with a 0.158 -pt decrease in the SWLS score) and education, with a mean difference between the satisfaction levels of respondents with higher and non-higher education of 1.253 pts (Table 6).

SES scores were shown to be significantly modulated by the overall score for the 33-Item Stigmatization Scale and one component of this scale, Sensitivity to the Opinions of Others (Table 6).

The two regression models described above explained approximately $35-40 \%$ of the variance in SWLS and SES scores, which should be considered a relatively high value. Presumably, this reflected the fact that psoriasis, despite being a burdensome illness, affects negatively only some limited aspects of patients' life.

\section{DISCUSSION}

Psoriasis is one of the most burdensome dermatoses, which results primarily from its chronic and recurrent character and spread of the lesions across large areas of the body, not infrequently visible to others. Distorted body image, skin ailments, and social rejection are the sources of stress which in turn exacerbates manifestations of the disease [13]. Similarly, the lesions can be activated or exacerbated by traumas, mechanical injuries to the skin, and infections. While it is postulated to reduce the risk of infection through vaccination [45], according to Kraśnicka et al. [46], this attitude is not universally accepted given the fear of vaccination side effects and disease induction.

DLQI scores for participants of the present study ranged between 0 and 28 pts. The mean DLQI score for the study group was 10.8 pts which is a relatively low value. Mean levels of stigmatization determined with the 33-Item and 6-Item Stigmatization Scales were 81.6 pts and 7.5 pts, respectively.

According to some previously published reports, mean DLQI scores for patients with psoriasis can be even lower: 9.16 pts according to Lin et al. [47], 8 pts according to Moradi et al. [48], and 6.13 pts according to Rencz et al. [49]. However, some authors reported higher DLQI scores than in the present study: 13.8 pts according to Sendrasoa et al. [50], 13.32 pts according to An et al. [51], and approximately $14 \mathrm{pts}$ according to Kowalewska et al. [52]. Finally, mean DLQI scores in some studies were only slightly lower than in our patients: 12 pts according to Martínez-García et al. [53], 12.4 pts according to Jung et al. [54], and 12.61 according to Kouris et al. [55].

Salaffi et al. [56] analyzed the quality of life in patients with psoriasis with the SF-36 questionnaire. The study demonstrated that psoriasis contributed to the deterioration of the quality of life in all domains of the SF-36 scale. 
Published data on the association between psoriasis severity and quality of life are inconclusive. While some authors did not find a link between the two variables [57], others demonstrated correlations between psoriasis severity and quality of life [58-61]. In our present study, the values of psychometric scales were stratified according to the location of psoriatic lesions. The comparative analysis included three groups: without psoriatic lesions $(30.63 \%$ of the study participants), with lesions limited only to some body parts (39.64\%), and with lesions spread across the entire body (29.73\%). The severity of the disease defined as above did not correlate with the overall quality of life and other generic psychometric measures nonspecific for skin diseases (SWLS, SES). However, significant between-group differences were observed regarding the two components of the 33-Item Stigmatization Scale: Guilt and Shame $(p=0.0010)$ and Positive Attitudes $(p=0.0321)$.

The study conducted by Soliman [62] included 199 Arabian patients with psoriasis. Up to $96 \%$ of the respondents experienced stigmatization of various degree, with the mean score for the 6-Item Stigmatization Scale of 7 pts. The vast majority of the respondents complained that others stared at their skin disease (83.4\%) and avoided them because of their skin condition $(78.9 \%)$. In that study, the level of stigmatization did not depend on such explanatory variables as gender, education, and visibility of the skin lesions. Lower stigmatization levels were found in older persons, with a longer duration of the disease and higher levels of illness acceptance. The study group presented with lower levels of satisfaction with life (scores between 5 and 38 pts, mean 21.2 pts), especially in persons with diminished quality of life. Deteriorated quality of life turned out to be the strongest predictor of stigmatization and decreased satisfaction with life, whereas higher levels of illness acceptance were associated with a greater satisfaction with life.

According to Hawro et al. [63], all patients with psoriasis experienced stigmatization of some degree because of their skin condition; higher levels of stigmatization were reported by persons whose skin lesions were visible to others $(p=0.025)$ and female patients $(p=0.001)$. The level of stigmatization was identified as the strongest determinant of the quality of life in the study group.

Perrot et al. [64] analyzed relationships between psoriasis severity, quality of life, and stigmatization, as well as psychosocial consequences of the disease in a group of 101 patients. The study showed that psoriasis severity had a weak effect on the quality of life and stigmatization levels. Dimitrov et al. [15] analyzed the level of stigmatization due to psoriasis in an Arabian population. Stigmatization was experienced by all 108 participants of the study. Mean scores for the 6-Item and 33-Item Stigmatization Scales were $5.6 \pm 4.5$ pts and $98.4 \pm 26.4 \mathrm{pts}$, respectively, with the Feeling of Being Flawed identified as the main contributor to stigmatization on the latter scale.

An interesting research question has been addressed by Sommer et al. [65], who analyzed the perception of stigma by patients with psoriasis, their families, and healthcare personnel. All three groups confirmed that psoriasis leads to stigmatization. The main form of stigmatization experienced by patients with psoriasis was self-stigma, which in the respondents' opinion imposed limitations on psychosocial functioning and role functioning. Interestingly, the problem of self-stigma was recognized not only by the patients but also by their families and healthcare personnel.

In the present study, the mean level of satisfaction with life measured with SWLS was 18.5 pts, i.e., slightly below the average. Meanwhile, the mean SES score was 26.8 pts, implying that the level of self-esteem in the study participants was slightly above the average.

We also analyzed the effects of selected clinicodemographic factors on the values of generic psychometric scales, SWLS and SES. The list of explanatory variables included patients' gender, age, and education, duration of psoriasis, and location of the skin lesions. Men turned out to present with higher SES and SWLS scores than women (27.5 vs. 26.0 pts and 18.7 vs. $18.3 \mathrm{pts}$, respectively). The age of the study respondents did not correlate significantly with either their satisfaction with life (SWLS) or selfesteem (SES). Respondents with higher education chose avoidance-focused style (SSU) and 
sought social contacts significantly more often than those with non-higher education. Duration of psoriasis did not correlate significantly with satisfaction with life (SWLS) and self-esteem (SES), with the coefficients of linear correlation of $-0.01 \quad(p=0.9546)$ and 0.05 ( $p=0.5985)$, respectively.

In a study of 81 psoriatics, Basińska and Drozdowska [66] found a moderate correlation between the body area covered with skin lesions and the level of satisfaction with life. In the study conducted by Soliman [62] in a group of 199 Arabian patients with psoriasis, quality of life turned out to be the strongest determinant of a higher sense of stigmatization ( $\beta$ coefficient $0.39,95 \%$ CI $0.30,0.47)$ and lower satisfaction with life $(-0.36,95 \% \mathrm{CI}-0.53,-0.20)$.

Solovan et al. [67] found a strong correlation between the presence of psoriasis and a decrease in the subject's body satisfaction, sexual satisfaction, social satisfaction, family satisfaction, professional satisfaction, and satisfaction concerning health condition $(p<0.01)$. Also, according to Eskin et al. [68], patients with psoriasis presented with lower levels of satisfaction with life than non-psoriatic controls.

Interestingly, Rzeszutek et al. [69] observed the lowest levels of satisfaction with life in patients with psoriasis with a negative self-image, whereas patients with a positive self-image did not differ in terms of their satisfaction with life from healthy controls. While satisfaction with life did not correlate significantly with the age of the participants of that study $(p>0.05)$, it turned out to be significantly higher in married than in non-married respondents $(18.63 \pm 6.13$ vs. $17.07 \pm 6.37$ pts, $p<0.01)$. Patients with higher education presented with more than the average level of satisfaction with life $(18.79 \pm 6.22 \mathrm{pts})$, whereas the mean value of this parameter in respondents with nonhigher education was $17.62 \pm 6.25$ pts.

In the present study, we analyzed the coefficients of linear correlation to verify how the values of the skin disease-specific scales (DLQI, both stigmatization scales) influenced the scores for generic psychometric measures (SWLS and SES).

The values of skin disease-specific scales correlated relatively strongly with generic psychometric measures. Correlations of DLQI and stigmatization scales with SWLS $(p=0.0000)$ and SES $(p=0.0000)$ were equally strong. All six correlations turned out to be inverse which implies that an increase in psoriasis-related discomfort had a detrimental effect on the overall well-being of the patients expressed by SWLS and SES scores. Clinicodemographic characteristics of the respondents, such as gender, age, location of psoriatic lesions, and duration of the disease, did not exert a significant effect on the analyzed psychometric measures. Satisfaction with life measured with SWLS was significantly modulated by the overall stigmatization level (the higher the sense of stigmatization, the lower the satisfaction with life, with a 1-pt increase in the stigmatization score corresponding to a 0.158 decrease in the satisfaction with life score, $p=0.0000$ ) and education (with mean satisfaction with life score for respondents with higher education being approximately 1.253 pts higher than in those with non-higher education, $p=0.0185$ ).

The results for SES were similar to those for SWLS, with the overall level of stigmatization measured with the 33-Item Stigmatization Scale $(p=0.0000)$ and one component of this scale, Sensitivity to the Opinions of Others $(p=0.0274)$, identified as significant determinants of the SES scores.

Psoriatics included in the study conducted by Kowalewska et al. [52] presented with low levels of satisfaction with life; men reported low levels of satisfaction with life slightly more often than women $(p=0.147)$. The mean score for the 6-Item Stigmatization Scale in the entire study group was 8.73 pts $( \pm 4.02)$ and did not differ significantly between women and men $(p=0.940)$. A mean DLQI score of 13.86 pts $( \pm 6.87)$ corresponded to a moderate-degree decrease in the quality of life. However, the analysis of individual scores suggested that the quality of life was substantially deteriorated in nearly half of the respondents. Similar to the study conducted by Soliman [62], poor quality of life was associated with lower satisfaction with life and a stronger sense of stigmatization.

Tzur Bitan et al. [70] demonstrated that in persons with low SES scores, the presence of 
psoriasis was associated with concomitant anxiety and depression $(p=0.001)$.

According to Brihan et al. [71], self-esteem measured with the SES decreased significantly with psoriasis severity, which had a detrimental effect on the quality of life. The difference in the self-esteem of patients with severe and mild psoriasis was statistically significant.

In the study conducted by Nazik [72], the presence of psoriasis, as well as lower self-esteem and poor body image, correlated significantly with a decrease in the quality of life (all relationships at $p=0.001$ ). A decrease in the self-esteem of patients with psoriasis was also reported by Hassani et al. [73] and Alariny et al. [74].

A strength of this study is the use of the skin disease-specific quality of life and stigmatization scales, along with two generic instruments, SWLS and SES; this provided a better insight into the mechanisms involved in the perception of the disease and its manifestations. However, given potential limitations of this study, such as the relatively small sample size, the results should be verified in a larger group and perhaps in a broader context, e.g., considering the effect of the emotional condition of the respondents on the quality of life and stigmatization. Another potential direction of future research could be a comparative analysis of the results obtained with the instruments used in the present study in groups of patients with different severity of psoriatic lesions and/ or patients before and after anti-psoriatic treatment.

To summarize, the results of this study imply that the sense of stigmatization contributes to a deterioration of the quality of life in patients with psoriasis. This relationship is more evident whenever the satisfaction with life and self-esteem of the patients are lower and can be additionally modulated by sociodemographic variables. The associations mentioned above are clinically relevant, given that psoriasis may coexist not only with somatic ailments but also psychosocial problems. Moreover, psoriasis is a more stigmatizing condition than other diseases that involve internal organs and thus are not visible to others, e.g., metabolic diseases, including diabetes mellitus, and cardiovascular disorders. Unlike people with psoriasis, patients with the aforementioned conditions are not stigmatized but may even experience sympathy from others.

It also needs to be stressed that problems coping with stressful situations and excessive emotional responses may exacerbate the course of psoriasis, which is probably reflected by the values of both the disease-specific and generic psychometric scales.

While the relationships mentioned above are relatively well understood, future research should verify whether they evolve in response to social changes and how. Perhaps, the evolution includes both perception of patients with psoriasis by others (more/less favorable attitude) and functioning of the patients in various psychosocial contexts. If such changes indeed occurred, they may warrant the adjustment of therapeutic approaches, especially in the psychological sphere, and/or modification of the forms and objectives of social campaigns supporting patients with psoriasis.

\section{CONCLUSION}

Most study respondents presented with low DLQI scores (mean 10.8 pts), slightly higher than the average levels of self-esteem (mean SES score of approximately $27 \mathrm{pts}$ ) and slightly lower than the average levels of satisfaction with life (SWLS score of 18.5 pts). Men had higher levels of satisfaction with life (SWLS) and higher self-esteem (SES) scores than women. The age of the respondents and duration of psoriasis did not correlate significantly with satisfaction with life (SWLS) and self-esteem (SES). Persons with higher education preferred avoidance-focused style (SSU) and sought social contacts significantly more often than respondents with non-higher education. The location of psoriatic lesions significantly affected two components of the 33-Item Stigmatization Scale, Shame and Guilt and Positive Attitudes, and was not associated with the overall quality of life (DLQI) and other generic psychometric measures (SWLS, SES). The values of the skin disease-specific scales correlated relatively strongly with generic psychometric measures. 
The powers of correlations between DLQI, stigmatization, SWLS and SES scores were similar, implying that an increase in psoriasis-related discomfort exerted a detrimental effect on the overall well-being of the patients expressed with SWLS and SES scores. Satisfaction with life turned out to be significantly modulated by overall stigmatization level on the 33-Item Stigmatization Scale (the stronger the sense of stigmatization, the lower the satisfaction with life) and education (respondents with higher education presented with higher satisfaction with life than those with non-higher education). The self-esteem of patients with psoriasis was significantly modulated by overall stigmatization level measured with the 33-Item Stigmatization Scale and one component of this scale, Sensitivity to the Opinions of Others.

\section{ACKNOWLEDGEMENTS}

The authors would like to thank the patients who participated in the survey.

Funding. This study and the journal's Rapid Service Fee were funded by Medical University of Bialystok, Poland. All authors had full access to all of the data in this study and take complete responsibility for the integrity of the data and accuracy of the data analysis. Neither honoraria nor other forms of payments were made for authorship.

Authorship. All named authors meet the International Committee of Medical Journal Editors (ICMJE) criteria for authorship for this manuscript, take responsibility for the integrity of the work as a whole, and have given final approval to the version to be published.

Authorship Contributions. Beata Kowalewska - was a major contributor in writing the manuscript and supervised this study. Was responsible for patient recruitment, data collection, data analysis, and drafting the manuscript. Barbara Jankowiak - was a major contributor in writing the manuscript, was involved in the development of the idea, data analysis, and drafting the manuscript. Elżbieta Krajewska- Kułak - was involved in the development of the idea and revised the manuscript critically for important intellectual content. Rafał Milewski - was involved in the development of the idea and revised the manuscript critically for important intellectual content. Marek Sobolewski - was involved in the development of the idea and revised the manuscript critically for important intellectual content. All authors read and approved the final manuscript.

Disclosures. Beata Kowalewska, Barbara Jankowiak, Elżbieta Krajewska - Kułak, Rafał Milewski, Marek Sobolewski have nothing to disclose.

Compliance with Ethics Guidelines. The research conforms with the Good Clinical Practice guidelines, and the procedures followed were in accordance with the Helsinki Declaration of 1975, as revised in 2000 (concerning the ethical principles for the medical community and forbidding release of the patient's name and initials, or the hospital evidence number). The study was reviewed and approved by the Bioethics Committee of the Medical University in Białystok (statute no. R-I-002/285/2018). Informed consent was obtained from all individual participants included in the study.

Data Availability. The datasets generated during and/or analyzed during the current study are available from the corresponding author on reasonable request.

Open Access. This article is licensed under a Creative Commons Attribution-NonCommercial 4.0 International License, which permits any non-commercial use, sharing, adaptation, distribution and reproduction in any medium or format, as long as you give appropriate credit to the original author(s) and the source, provide a link to the Creative Commons licence, and indicate if changes were made. The images or other third party material in this article are included in the article's Creative Commons licence, unless indicated otherwise in a credit line to the material. If material is not included 
in the article's Creative Commons licence and your intended use is not permitted by statutory regulation or exceeds the permitted use, you will need to obtain permission directly from the copyright holder. To view a copy of this licence, visit http://creativecommons.org/licenses/bync/4.0/.

\section{REFERENCES}

1. Hong J, Koo B, Koo J. The psychosocial and occupational impact of chronic skin disease. Dermatol Ther. 2008;21:54-9. https://doi.org/10.1111/j.15298019.2008.00170.x.

2. Inanir I, Aydemir O, Gündüz K, Danaci AE, Türel A. Developing a quality of life instrument in patients with psoriasis: the Psoriasis Quality of Life Questionnaire (PQLQ). Int J Dermatol. 2006;45:234-8. https://doi.org/10.1111/j.1365-4632.2005.02448.x.

3. Jensen P, Skov L. Psoriasis and obesity. Dermatology. 2016;232(6):633-9. https://doi.org/10.1159/ 000455840 .

4. Kunz M, Simon JC, Saalbach A. Psoriasis: obesity and fatty acids. Front Immunol. 2019;10: 1807. https://doi.org/10.3389/fimmu.2019.01807.

5. Owczarczyk-Saczonek A, Placek W. Compounds of psoriasis with obesity and overweight. Postepy Hig Med Dosw (Online). 2017;71(1):761-72. https:// doi.org/10.5604/01.3001.0010.3854.

6. Kong $\mathrm{Y}$, Zhang $\mathrm{S}, \mathrm{Wu} \mathrm{R}$, et al. New insights into different adipokines in linking the pathophysiology of obesity and psoriasis. Lipids Health Dis. 2019;18(1):171. https://doi.org/10.1186/s12944019-1115-3.

7. Rendon A, Schäkel K. Psoriasis pathogenesis and treatment. Int J Mol Sci. 2019;20(6):1475. https:// doi.org/10.3390/ijms20061475.

8. Frischknecht L, Vecellio M, Selmi C. The role of epigenetics and immunological imbalance in the etiopathogenesis of psoriasis and psoriatic arthritis. Ther Adv Musculoskelet Dis. 2019;11:17-59. https://doi.org/10.1177/1759720X19886505.

9. Drvar DL, Vlahinić T, Maleš Ž, Turčić P, Čeović R. A modern approach to the treatment of plaque psoriasis. Acta Pharm. 2019;69(4):511-23. https://doi. org/10.2478/acph-2019-0047.

10. Langley RG, Krueger GG, Griffiths CE. Psoriasis: epidemiology, clinical features, and quality of life.
Ann Rheum Dis. 2005;64(Suppl 2):ii18-23. https:// doi.org/10.1136/ard.2004.033217.

11. Oji V, Luger TA. The skin in psoriasis: assessment and challenges. Clin Exp Rheumatol. 2015;33(5 Suppl 93):S14-9.

12. Petraškienè $\mathrm{R}$, Valiukevičienè $\mathrm{S}$, Macijauskienė J. Associations of the quality of life and psychoemotional state with sociodemographic factors in patients with psoriasis. Medicina. 2016;52(4): 238-43. https://doi.org/10.1016/j.medici.2016.07. 001.

13. Boehncke WH, Schön MP. Psoriasis. Lancet. 2015;386(9997):983-94. https://doi.org/10.1016/ S0140-6736(14)61909-7.

14. Czykwin E. Stygmat społeczny. Warszawa: Wydawnictwo Naukowe PWN; 2020.

15. Dimitrov D, Matusiak $€$, Szepietowski JC. Stigmatization in Arabic psoriatic patients in the United Arab Emirates-a cross sectional study. Adv Dermatol Allergol. 2019;36(4):425-30. https://doi.org/ 10.5114/ada.2018.80271.

16. Zięciak T, Rzepa T, Król J, Żaba R. Stigmatization feelings and depression symptoms in psoriasis patients. Psychiatr Pol. 2017;51:1153-63. https:// doi.org/10.12740/PP/68848.

17. Schmid-Ott G, Schallmayer S, Calliess IT. Quality of life in patients with psoriasis and psoriasis arthritis with a special focus on stigmatization experience. Clin Dermatol. 2007;25:547-54. https://doi.org/10. 1016/j.clindermatol.2007.08.008.

18. Hawro T, Janusz I, Zalewska A, Miniszewska J. Jakość życia i stygmatyzacja a nasilenie zmian skórnych i świądu u osób chorych na łuszczycę. W Rzepa T, Szepietowski J, Żaba R. Psychologiczne i medyczne aspekty chorób skóry. Wrocław Poland, Cornetis; 2011. p. 42-51.

19. Hrehorów E, Salomon J, Matusiak $\mathrm{E}$, Reich A, Szepietowski JC. Patients with psoriasis feel stigmatized. Acta Derm Venereol. 2012;92:67-72. https://doi.org/10.2340/00015555-1193.

20. Zill JM, Dirmaier J, Augustin M, et al. Psychosocial distress of patients with psoriasis: protocol for an assessment of care needs and the development of a supportive intervention. JMIR Res Protoc. 2018;7: e22. https://doi.org/10.2196/resprot.8490.

21. Kostyła M, Tabała K, Kocur J. Illness acceptance degree versus intensity of psychopathological symptoms in patients with psoriasis. Adv Dermatol Allergol. 2013;30:134-9. https://doi.org/10.5114/ pdia.2013.35613. 
22. Hrehorów E, Reich A, Szepietowski J. Jakość życia chorych na łuszczycę: zależność od świądu, stresu i objawów depresyjnych. Dermatol Klin. 2007;9: 19-23.

23. Martínez-Ortega JM, Nogueras P, Muñoz-Negro JE, Gutiérrez-Rojas L, González-Domenech P, Gurpegui M. Quality of life, anxiety and depressive symptoms in patients with psoriasis: a case-control study. J Psychosom Res. 2019. https://doi.org/10.1016/j. jpsychores.2019.109780.

24. Gupta MA, Gupta AK. Psychiatric and psychological comorbidity in patients with dermatologic disorders: epidemiology and management. Am J Clin Dermatol. 2003;4(12):833-42. https://doi.org/10. 2165/00128071-200304120-00003.

25. Miękoś-Zydek B, Ryglewska A, Lassota-Falczewska M, Czyż P, Kaszuta A. Quality of life in psoriatic patients. Adv Dermatol Allergol. 2006;23(6):273-7.

26. Rapp DA, Brenes GA, Felman SR, et al. Anger and acne: implications for quality of life, patient satisfaction and clinical care. $\mathrm{Br} \mathrm{J}$ Dermatol. 2004;151(1):183-9. https://doi.org/10.1111/j.13652133.2004.06078.x.

27. Zacharie R, Zacharie C, Ibsen H, Morternsen JT, Wulf HC. Dermatology life quality idem: data Danish inpatients and outpatients. Acta Derm Venerol. 2003;suppl 2:78-86. https://doi.org/10. 1080/000155500750012153.

28. Kowalewska B, Krajewska-Kułak E, Wrońska I, Niczyporuk W, Sobolewski M. Self-assessment of quality of life in patients with dermatological disorders. Dermatol Klin. 2010;12(2):106-13.

29. Finlay AY, Khan GK. Dermatology Life Quality Index (DLQI) - a simple practical measure for routine clinical use. Clin Exp Dermatol. 1994;19(3): 210-6. https://doi.org/10.1111/j.1365-2230.1994. tb01167.x.

30. Gerdes S, Zahl VA, Weichenthal M, Mrowietz U. Smoking and alcohol intake in severely affected patients with psoriasis in Germany. Dermatology. 2010;220:38-43. https://doi.org/10.1159/ 000265557 .

31. Fortes C, Mastroeni S, Leffondré K, et al. Relationship between smoking and the clinical severity of psoriasis. Arch Dermatol. 2005;141:1580-4. https:// doi.org/10.1001/archderm.141.12.1580.

32. Kirby B, Richards HL, Mason DL, Fortune DG, Main CJ, Griffiths CE. Alcohol consumption and psychological distress in patients with psoriasis. $\mathrm{Br} \mathrm{J}$ Dermatol. 2008;158:138-40. https://doi.org/10. 1111/j.1365-2133.2007.08299.x.
33. Komorowska OR, Szczerkowska-Dobosz A, Purzycka-Bohdan D, Rawicz-Zegrzda D, Dudziak M. Łuszczyca jako czynnik ryzyka rozwoju chorób serca i naczyń. Przegl Dermatol. 2014;101:500-6. https://doi.org/10.5114/dr.2014.46953.

34. Türel Ermertcan A, Temeltaş G, Deveci A, et al. Sexual dysfunction in patients with psoriasis. J Dermatol. 2006;33:772-8. https://doi.org/10. 1111/j.1346-8138.2006.00179.x.

35. Dauendorffer JN, Ly S, Beylot-Barry M. Psoriasis and male sexuality. Ann Dermatol Venereol. 2019;146(4):273-8. https://doi.org/10.1016/j. annder.2019.01.021.

36. Szepietowski J, Salomon J, Finlay AY, et al. Dermatology Life Quality Index (DLQI): Polish version. Dermatol Klin. 2004;6(2):63-70.

37. Lu Y, Duller P, van der Valk PGM. Helplessness as predictor of perceived stigmatization in patients with psoriasis and atopic dermatitis. Dermatol Psychosom. 2003;4:146-50.

38. Hrehorów E, Szepietowski J, Reich A, Evers AWM, Ginsburg IH. Narzedzia do oceny stygmatyzacji u chorych na łuszczycę: polskie wersje językowe. Derm Klin. 2006;8:253-8.

39. Ginsburg IH, Link BG. Feelings of stigmatization in patients with psoriasis. J Am Acad Dermatol. 1989;20:53-63. https://doi.org/10.1016/s01909622(89)70007-4.

40. Diener E, Emmons RA, Larsen RJ, Griffin S. The satisfaction with life scale. J Pers Assess. 1985;49(1): 71-5. https://doi.org/10.1207/s15327752jpa4901_ 13.

41. Juczyński Z. NPPPZ-Narzędzia Pomiaru w Promocji I Psychologii Zdrowia. Pracownia Testów Psychologicznych Polskiego Towarzystwa Psychologicznego, Warszawa (2012).

42. Dzwonkowska I, Lachowicz-Tabaczek K, Łaguna M. Samoocena i jej pomiar. SES. Skala Samooceny Rosenberga. Warszawa: Pracownia Testów Psychologicznych; 2008.

43. Stanisz A. Przystępny kurs statystyki z zastosowaniem STATISTICA PL na przykładach $z$ medycyny. Tom 1. Wyd. Kraków: StatSoft Polska; 2007.

44. Stanisz A. Przystępny kurs statystyki $\mathrm{z}$ zastosowaniem STATISTICA PL na przykładach $\mathrm{z}$ medycyny. Tom 2. Wyd. Kraków: StatSoft Polska; 2007.

45. Wine-Lee L, Keller SC, Wilck MB, Gluckman SJ, Van Voorhees AS. From the Medical Board of the 
National Psoriasis Foundation: vaccination in adult patients on systemic therapy for psoriasis. J Am Acad Dermatol. 2013;69(6):1003-13. https://doi. org/10.1016/j.jaad.2013.06.046.

46. Kraśnicka J, Krajewska-Kułak E, Klimaszewska K, et al. Mandatory and recommended vaccinations in Poland in the views of parents. Hum Vaccin Immunother. 2018;14(12):2884-93. https://doi. org/10.1080/21645515.2018.1496766.

47. Lin TY, See LC, Shen YM, Liang CY, Chang HN, Lin YK. Quality of life in patients with psoriasis in northern Taiwan. Chang Gung Med J. 2011;34: 186-96.

48. Moradi M, Rencz F, Brodszky V, Moradi A, Balogh $\mathrm{O}$, Gulácsi L. Health status and quality of life in patients with psoriasis: an Iranian cross-sectional survey. Arch Iran Med. 2015;18:153-9.

49. Rencz F, Gulácsi L, Péntek M, et al. DLQI-R scoring improves the discriminatory power of the Dermatology Life Quality Index in patients with psoriasis, pemphigus and morphea. Br J Dermatol. 2020;182: 1167-75. https://doi.org/10.1111/bjd.18435.

50. Sendrasoa FA, Razanakoto NH, Ratovonjanahary V, et al. Quality of life in patients with psoriasis seen in the Department of Dermatology, Antananarivo, Madagascar. Biomed Res Int. 2020;2020(14): 9292163. https://doi.org/10.1155/2020/9292163.

51. An JG, Liu YT, Xiao SX, Wang JM, Geng SM, Dong YY. Quality of life of patients with neurodermatitis. Int J Med Sci. 2013;10:593-8. https://doi.org/10. $7150 /$ ijms.5624.

52. Kowalewska B, Cybulski M, Jankowiak B, KrajewskaKułak E. Acceptance of illness, satisfaction with life, sense of stigmatization, and quality of life among people with psoriasis: a cross-sectional study. Dermatol Ther. 2020;10:413-30. https://doi.org/10. 1007/s13555-020-00368-w.

53. Martínez-García E, Arias-Santiago S, ValenzuelaSalas I, Garrido-Colmenero C, García-Mellado V, Buendía-Eisman A. Quality of life in persons living with psoriasis patients. J Am Acad Dermatol. 2014;71:302-7. https://doi.org/10.1016/j.jaad. 2014.03.039.

54. Jung S, Lee M, Suh D, Shin HT, Suh DC. The association of socioeconomic and clinical characteristics with health-related quality of life in patients with psoriasis: a cross-sectional study. Health Qual Life Outcomes. 2018;16:180. https://doi.org/10. 1186/s12955-018-1007-7.

55. Kouris A, Christodoulou C, Stefanaki C, et al. Quality of life and psychosocial aspects in Greek patients with psoriasis: a cross-sectional study. An
Bras Dermatol. 2015;90:841-5. https://doi.org/10. 1590/abd1806-4841.20154147.

56. Salaffi F, Carotti M, Gasparini S, Intorcia M, Grassi $\mathrm{W}$. The health-related quality of life in rheumatoid arthritis, ankylosing spondylitis, and psoriatic arthritis: a comparison with a selected sample of healthy people. Health Qual Life Outcomes. 2009;7: 25. https://doi.org/10.1186/1477-7525-7-25.

57. Fortune DG, Main CJ, O'Sullivan TM, Griffiths CEM. Quality of life in patients with psoriasis: the contribution of clinical variables and psoriasisspecific stress. Br J Dermatol. 1997;137:755-60.

58. Rapp SR, Feldman SR, Excum ML, Fleischer AB, Reboussin DM. Psoriasis causes as much disability as other major medical diseases. J Am Acad Dermatol. 1999;41:401-6. https://doi.org/10.1016/ s0190-9622(99)70112-x.

59. Rapp SR, Cottrell CA, Leary MR. Social coping strategies associated with quality of life decrements among psoriasis patients. Br J Dermatol. 2001;145: 610-6. https://doi.org/10.1046/j.1365-2133.2001. 04444.x.

60. Uttjek M, Dufaker M, Nygren L, Stenberg B. Determinants of quality of life in a psoriasis population in northern Sweden. Acta Derm Venereol. 2004;84: 37-43. 00015550310015833.

https://doi.org/10.1080/

61. Al-Mazeedi K, El-Shazly M, Al-Ajmi HS. Impact of psoriasis on quality of life in Kuwait. Int J Dermatol. 2006;45(4):418-24. https://doi.org/10.1111/j.13654632.2006.02502.x.

62. Soliman MM. Feeling of stigmatization and satisfaction with life among Arabic psoriatic patients. Saudi Pharm J. 2020;28(12):1868-73. https://doi. org/10.1016/j.jsps.2020.11.013.

63. Hawro M, Maurer M, Weller K, et al. Lesions on the back of hands and female gender predispose to stigmatization in patients with psoriasis. J Am Acad Dermatol. 2017;76(4):648-654.e2. https://doi.org/ 10.1016/j.jaad.2016.10.040.

64. Perrott SB, Murray AH, Lowe J, Mathieson CM. The psychosocial impact of psoriasis: physical severity, quality of life, and stigmatization. Physiol Behav. 2000;70(5):567-71. https://doi.org/10.1016/s00319384(00)00290-0.

65. Sommer R, Augustin M, Mrowietz U, Topp J, Schäfer I, von Spreckelsen R. Perception of stigmatization in people with psoriasis-qualitative analysis from the perspective of patients, relatives and healthcare professionals. Hautarzt. 2019;70(7): 520-6. https://doi.org/10.1007/s00105-019-4411-y (German). 
66. Basińska MA, Drozdowska M. Emotional intelligence as an indicator of satisfaction with life of patients with psoriasis. Postepy Dermatol Alergol. 2013;30(6):365-72. https://doi.org/10.5114/pdia. 2013.39435 .

67. Solovan C, Marcu M, Chiticariu E. Life satisfaction and beliefs about self and the world in patients with psoriasis: a brief assessment. Eur J Dermatol. 2014;24(2):242-7. https://doi.org/10.1684/ejd. 2014.2295 .

68. Eskin M, Savk E, Uslu M, Küçükaydoğan N. Social problem-solving, perceived stress, negative life events, depression and life satisfaction in psoriasis. J Eur Acad Dermatol Venereol. 2014;28(11):1553-9. https://doi.org/10.1111/jdv.12355.

69. Rzeszutek M, Podkowa K, Pięta M, Pankowski D, Cyran-Stemplewska S. Comparative study of life satisfaction among patients with psoriasis versus healthy comparison group: the explanatory role of body image and resource profiles. Qual Life Res. 2021;30(1):181-91. s11136-020-02621-3.

70. Tzur Bitan D, Krieger I, Comaneshter D, Cohen AD, Feingold D. The association between the socioeconomic status and anxiety-depression comorbidity in patients with psoriasis: a nationwide populationbased study. J Eur Acad Dermatol Venereol. 2019;33(8):1555-61. https://doi.org/10.1111/jdv. 15651.

71. Brihan I, Ianoşi SL, Boda D, Hălmăjan A, Zdrîncă M, Fekete LG. Implications of self-esteem in the quality of life in patients with psoriasis. Exp Ther Med. 2020;20(6):202. https://doi.org/10.3892/etm.2020. 9332.

72. Nazik H, Nazik S, Gul FC. Body image, self-esteem, and quality of life in patients with psoriasis. Indian Dermatol Online J. 2017;8(5):343-6. https://doi. org/10.4103/idoj.IDOJ_503_15.

73. Hassani F, Koraei A, Yaghoobi R, Zarea K. An evaluating of the relationship between body image, body satisfaction, depression, marital quality, and self-esteem in patients with psoriasis. Psychol Health Med. 2021;26(4):467-77. https://doi.org/10. 1080/13548506.2020.1766093.

74. Alariny AF, Farid CI, Elweshahi HM, Abbood SS. Psychological and sexual consequences of psoriasis vulgaris on patients and their partners. J Sex Med. 2019;16(12):1900-11. https://doi.org/10.1016/j. jsxm.2019.08.017. 